YUJIE HUANG ${ }^{1}$

E-mail: vegetablemonkey@sjtu.edu.cn

HAO HU, Ph.D. ${ }^{1}$

(Corresponding author)

E-mail: hhu@sjtu.edu.cn

JINJIN CHEN ${ }^{2}$

E-mail: jj_chen@sjtu.edu.cn

LEI DAI, Ph.D. ${ }^{1}$

E-mail: sjtudailei@163.com

${ }^{1}$ School of Naval Architecture, Ocean

and Civil Engineering

Shanghai Jiao Tong University

Shanghai, 200240, China

${ }^{2}$ School of Electronic Information and Electrical

Engineering

Shanghai Jiao Tong University

Shanghai, 200240, China
Traffic Planning

Original Scientific Paper

Submitted: 18 Apr. 2020

Accepted: 16 Nov. 2020

\title{
DECISION MAKING ON GOVERNMENT SUBSIDY FOR HIGHWAY PUBLIC-PRIVATE PARTNERSHIP PROJECTS IN CHINA USING AN ITERATION GAME MODEL
}

\begin{abstract}
Government subsidy is an important responsibility of fiscal expenditure in public-private partnership (PPP) projects. However, an improper subsidy strategy may cause over-compensation or under-compensation. In this research, an iteration game model combining game theory and real option is established to describe the periodic decision-making process. The strategy game model is applied to characterize the behavioral interactions between stakeholders, and the real option theory is used to predict the project performance under the influence of their decisions. Besides, two new indicators, the efficiency of fund (SE) and the total extra cost paid by the private sector (ME), are proposed to evaluate the extra project revenue caused by each unit of the subsidy and the incentive effects of the subsidy. Consequently, the preliminary results indicate that a periodic and iterative negotiations regarding the subsidy will effectively improve the effciency of fund compared to the traditional way. The results also show that it is important for the public sector to give incentives, encouraging the private sector to make more efforts on the project, rather than merely providing fund support. Further study will focus on more detailed and complicated behaviors of stakeholders based on the model proposed in this paper.
\end{abstract}

\section{KEYWORDS}

PPP (public-private partnership); government subsidy; game theory; real option; decision making; highway case study.

\section{INTRODUCTION}

China is now the biggest PPP (public-private partnership) market in the world with a total investment of over 1.85 trillion US dollars, but the transaction volume of the Chinese PPPs has been declining in recent years [1]. That is mainly because many spurious PPP projects have been terminated, as they may disorder and mislead the Chinese PPP development [2]. One typical kind of spurious PPPs is that the private sectors utilize the subsidy to get the revenue guarantee from local government. However, government subsidy is a very important item in infrastructure concession agreements. Since most of the infrastructures have public nature rather than profitability (the nature of earning money), it is necessary to subsidize the projects with government support in order to stimulate the private investment and let private sectors obtain reasonable revenue.

However, government subsidy negotiation is mostly prevalent among those projects with operating income that cannot cover the construction and operation cost, such as highway and urban railway projects. According to the statistic of Bridata, a technology company focusing on the big data in Chinese PPP, $65.2 \%$ of a total of 259 highway PPP agreements incorporates the clauses of viability gap funding, a kind of government subsidy applied in PPP. Highway projects are usually characterized as 
large-scale investment and various unpredictable risks during a very long concession period. Therefore, the granting of a government subsidy to the private partner is in certain circumstances a preferred choice for risk mitigation in such projects [3].

Although government subsidy is a useful fiscal tool of both guaranteeing the minimal revenue of the private sector and sharing revenue risk in highway PPP agreements, an improper subsidy strategy could backfire. An under-compensation scheme will probably undermine the profitability of the SPV (special purpose vehicle), causing a decrease in the willingness of the private sector to invest in PPP, while an over-compensation scheme may be a fiscal waste for the public sector and erode the motivation of the private sector to make efforts in the concession period. Thus, how to design a public subsidy is crucial question for policymakers. Abundant relevant studies have been done on this scientific problem. Generally, the decision-making process can be divided into two steps.

The first step is to conduct a prediction of project revenue, for it directly impacts the decision of concession items (e.g. concession period, concession price, government subsidy, and capital structure). To forecast the project revenue, net present value (NPV) analysis, Monte Carlo Simulation, real option, and system dynamics methods have been commonly applied in the existing research.

The net present value (NPV) method is the most traditional way to conduct cash flow analysis on the projects. The discounted cash flow (DCF) model, the kernel of the NPV method, is still used as the basis of other methods. Based on the DCF model, studies developed the BOT (build-operate-transfer) concession model (BOTCcM) to determine the concession items in a way that can protect both the interest of the government and of the private sectors [4].

However, the traditional DCF model does not consider the uncertainty factors (volatility of parameters) in the model. Therefore, in some studies, random assumptions on the parameters (e.g. user demand, price, maintenance cost, and discounted rate) are made, and Monte Carlo simulation is conducted to obtain the distribution of the NPV. By combing WACC (weighted average cost of capital) and mean-variance method, the NPV-at-Risk method is proposed to make decisions for the infrastructure project based on the NPV at a certain confidence level [5]. Some studies modify the BOTCcM by taking into consideration the risk impact on estimation of various economic variables in the model [6].

Real option approach has also become a useful way to forecast the uncertain revenue in toll concessions. Moreover, this method is more suitable for studies on concession items such as government guarantee [7], subsidies [8], and fare allocation, because these items can be essentially regarded as real options. Brandão et al. conducted a detailed case study on Metro Line 4 of the São Paulo Subway System, where the real option approach is used to analyze the effect of the minimum demand guarantee (MDG) on value and risk [9]. Galera et al. think that the project must be assessed within the real options framework, because traditional methods of project valuation are inappropriate when they incorporate flexibility and uncertainty [3].

Besides, system dynamics has proved to be another alternative to simulate revenue. By applying system dynamics, the causal relationship among the influencing factors in the model is considered [10]. The causal loop diagram would be used to analyze the relevant relationships among various factors influencing the concession period, and a stock-flow diagram would be used to build the decision-making model of the concession period [11].

After predicting the revenue of the projects, stakeholders should take the second step to make decisions on concession items. Since there are various stakeholders, their conflict of interest has to be considered in decision making. For instance, in their improved concession model $\mathrm{Hu}$ and Zhu take social welfare into account, which was usually ignored in previous studies [12]. Feng et al. established a multi-objective optimization model, in which key concessionary items act as decision variables, and public and private interests are represented by two sub-objectives [13].

Game theory is widely used to analyze this game-nature process. Shen et al. introduced a new method called the BOT bargaining concession model $(\mathrm{BOTBaC})$ which takes into account the bargaining behavior of the investor and the government [14]. Sharafi et al. investigates certain sharing mechanisms based on cooperative game concepts, including the core, the nucleolus, and the Shapley value to address the fare allocation of excess benefit or cost in a PPP project [15]. Feng et al. find that the optimal concession period for a PPP toll road can be effectively identified through mathematical gaming 
model. The results also provide useful guidance for public and private sectors for PPP projects in negotiations on related issues [16].

Traditionally, a government subsidy is merely regarded as a supplement for contractors' revenue to improve the financial feasibility and it does not take the efficiency of public administration into consideration [17]. Efficiency is always related to application of limited financial resources, minimal organizational costs, and efforts in pursue of target results [18]. As previously stated, the above-mentioned approaches can be effective tools for decision making regarding the government subsidy based on the revenue. However, these studies might have been more reasonable if they had taken into consideration the influence of the subsidy on the private sector's behavior (i.e., the private sector may make excess efforts on the project to get more benefit).

The incentive effects of the government subsidy have been proved by many empirical studies of public R\&D (Research and Development) expenditure in business $[19,20]$. Based on large sample analysis, some studies found the curve of the subsidy effect, an inverse U shape, which means the subsidy may also make the recipient slack $[21,22]$. Similar$1 y$, an interaction between the behaviors of the public sector and the private sector in making decisions on the government support in a PPP project is also believed to exist.

In this paper, an improved subsidy mechanism is defined as the fund support that can fully arouse the motivation of the contractors to devotedly carry out operation and maintenance works. Since the government always needs to give support to many public service projects with a limited budget, it should pay more attention to the efficiency of fund use instead of just filling the gap.

The paper is organized as follows: the importance of the topic is established in the introduction. In the model development section, the iteration game model combining real option theory and game theory is proposed to get the revenue functions of both the public and the private sectors. Then, the decision-making section presents how to get the game results from above mentioned model and introduces some indexes to evaluate the subsidy strategy obtained. A case study is carried out based on the Peking Xing Yan highway PPP project in China to verify the model. Finally, based on the results, the conclusion regarding policy implications and implementation suggestions for the government are discussed.

\section{MODEL DEVELOPMENT}

Traditionally, the government sector and private sector reach an agreement on the government subsidy before the project starts and they execute this agreement during the whole concession period. However, that may cause over-compensation or under-compensation, because it is difficult to accurately predict the revenue, especially for a long concession like toll roads.

Therefore, this paper focuses on an iteration decision process as follows:

1) The decision on government subsidy and the LOE (level of efforts, the degree of making excess efforts on the project) of the private sector will affect each other. The decision process on the subsidy and LOE can be regarded as a game process.

2) The decision results can be renegotiated sometime in the concession period when the previous decision is not suitable for the present situation.

3) There is a dynamic circulation between the game process and the performance of the project. Every game result will affect the performance of the project in the following years, and the performance will in turn affect the next game result.

The logical framework is shown in Figure 1. Effect 1 refers to the fact that the decisions influence the performance of the project. Effect 2 means that the performance affects the next decision.

In this way, the stakeholders can alter their decisions through renegotiation during the operation period based on the performance of the project. It is a better way to balance the benefits for these two parties.

In this section, a model combining real option theory and game theory is proposed to determine the government subsidy for a feasibility gap fund PPP agreement. Real option theory is applied to predict the annual demand of the project based on the influence of the decisions of the stakeholders. Then, strategic game theory is used to make decisions on both the subsidy and the LOE based on the project performance. The following content will explain how to combine these two theories and establish an iteration subsidy decision model for a feasibility gap fund PPP agreement. 


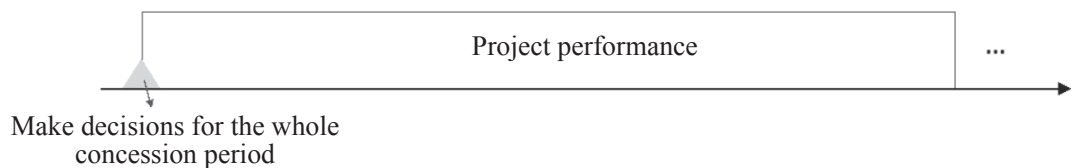

a) Traditional way

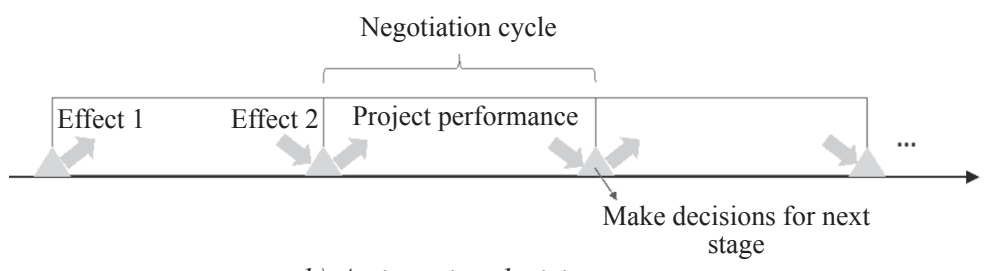

b) An iteration decision proces

Figure 1-Logical framework of the model

\subsection{Variables}

Table 1 lists main variables within the model. Other variables that are the variants of these will be subsequently explained.

$\alpha$ and $\beta$ are decision variables of the model.

$\alpha$ : The subsidy ratio by government. Considering that the subsidy should stimulate the growth of demand, this paper adopts price support. If the private sector sets the unit price at $P$, the local government should pay $\alpha P$ for each unit of service of this project, while the users pay the remaining $(1-\alpha) P$ for a unit of service. But when the local government chooses not to give any subsidy, the users should pay $P$ as the unit price. Lower unit price leads to more demand for the service.

$\beta$ : Level of efforts (LOE) of the private sector. It represents the improvement of the level of service of the project caused by the extra cost that the private sector pays for annual maintenance and operation. According to the principle of economics, the improvement of the level of service should obey diminishing marginal effectiveness and the extra cost should obey increasing marginal cost. Therefore, given an annual maintenance cost of $M$, and a level of service of $w$, the excess annual cost is assumed to be $M \beta^{2}$, and the level of service can be improved by $w \ln (1+\beta)$ when LOE is $\beta$.

\subsection{Assumptions}

1) The objective of the public sector is to obtain maximal social benefit. In this paper, the social benefit is defined as the sum of the residual value of the project and the improvement part of the level of service enjoyed by the users.

2) The objective of the private sector is to get maximal revenue.

Table 1 - Main variables in the model

\begin{tabular}{||l|l|c|l||}
\hline \hline Notation & \multicolumn{1}{|c|}{ Definition } & Notation & \multicolumn{1}{c||}{ Definition } \\
\hline \hline$\alpha$ & Subsidy ratio & $n$ & Renegotiation round \\
\hline$\beta$ & Level of efforts (LOE) & $R V$ & Residual value of the project \\
\hline$P$ & Unit price & $B$ & Social benefit caused by improvement in $w$ \\
\hline$w$ & Level of service & $E$ & Equity capital \\
\hline$M$ & Annual maintenance and operation cost & $\theta$ & Equity share of the public sector \\
\hline$Q$ & Demand (number of users) & $I$ & Total initial investment \\
\hline$\mu$ & Annual growth rate of demand & $r r$ & Residual rate \\
\hline$t$ & Time (year) & $R_{G, n}$ & $\begin{array}{l}\text { Expected revenue of the public sector obtained in } \\
\text { round } n\end{array}$ \\
\hline$\sigma$ & Volatility & $R_{P, n}$ & $\begin{array}{l}\text { Expected revenue of the private sector obtained in } \\
\text { round } n\end{array}$ \\
\hline$z$ & Standard Wiener process & $d$ & Discounted rate \\
\hline$S_{G}^{i}$ & Strategy $i$ of the public sector & $\tilde{S}_{G}$ & Total subsidy the public sector provides \\
\hline$S_{P}^{j}$ & Strategy $j$ of the private sector & $\tilde{R}_{P}$ & Total revenue the private sector gets \\
\hline$T_{c}$ & Length of the concession period & $S E$ & The efficiency of fund (subsidy using) \\
\hline$T_{r}$ & Length of the renegotiation cycle & $M e$ & Total excess cost the private sector pays \\
\hline
\end{tabular}


3) Subsidy strategy can be renegotiated at any time of the concession period. In this way, the subsidy can fit in with the status quo of the project and balances the objectives of both two parties. In this paper, the renegotiation is considered to be a periodic action that happens every $T_{r}$ years.

4) The level of efforts (LOE) can be evaluated by the extra cost on annual maintenance and operation, and the improvement of the level of service. Consequently, LOE directly effects the performance of the project.

5) Renegotiations cost nothing to the public sector or private sectors. It is believed that the renegotiation on the subsidy will only lead to a better project performance. So, the benefits outweigh the renegotiation cost, and the cost can be omitted.

6) Renegotiations are instantaneous, which means there is no delay in the conduct of the new subsidy strategy. And the renegotiations happen at the end of the last year of a cycle or at the beginning of the first year of a cycle.

\subsection{Demand prediction based on real option theory}

As is stated in the existing literature applying real option to revenue prediction, the quantity of project users can be modeled as a Geometric Brownian motion diffusion process [23]:

$$
d Q=\mu Q d t+\sigma Q d z
$$

where:

$d Q$ - incremental change in the quantity of users in one time interval

$\mu$ - annual growth rate of the quantity

$d t$ - time interval, one year

$\sigma$ - volatility

$z$ - standard Wiener process.

From Equation 1, a discretization form can be obtained as:

$$
Q_{t+1}=Q_{t} e^{\left(\mu-\frac{\sigma^{2}}{2}\right) \Delta t+\sigma d z}
$$

Then, some modifications should be made to the above model in order to take into account the influence of the government subsidy and LOE of the operator on the demand. The government subsidy can decrease the price that the users should pay, and thus the service attracts more users. Also, LOE should reflect the improvement of level of service, which also stimulates the growth of the volume. Consequently, the annual growth rate $\mu$ is assumed to be:

$\mu=b \cdot \frac{w[1+\ln (1+\beta)]}{P(1-\alpha)}$

where:

$b$ - value determined by expert experience

$P$ - unit price of this public service

$w$ - general level of service offered by the project

operator. It can be evaluated by the unit price.

\subsection{Iteration game model}

Based on the assumption that all renegotiations are instantaneous, the negotiation on the subsidy is regarded as a complete information static game process. Both participants have two kinds of strategies, and they can only choose one alternative in the negotiation.

As for the public sector, the strategy set can be represented as follows:

$S_{G}=\left(S_{G}^{1}, S_{G}^{0}\right)=$ (give subsidy in following years, do not give any subsidy)

As for the private sector (i.e., the project operator), the strategy set can be represented as follows: $S_{P}=\left(S_{P}^{1}, S_{P}^{0}\right)=$ (make efforts, be slack)

The game result $\boldsymbol{S}=\left(S_{G}^{i}, S_{P}^{j}\right) \quad(i, j=0,1)$ will affect the growth rate $\mu$ as shown in Table 2 .

When the stakeholders make decisions: $\boldsymbol{S}=\left(S_{G}^{i}, S_{P}^{j}\right)$, the corresponding $\mu_{i j}$ will be used to predict the demand by Equation 2. And the demand series $\left\{Q_{i j}\right\}$ obtained from $\mu_{i j}$ will be used to calculate the revenue of the private sector and the social benefit.

Next, the revenue function and the social benefit function will be given. Suppose that it is now round $n(n=0,1 \ldots)$ in the iteration process, and the two parties renegotiate every $T_{r}$ years. $T_{c}$ is the length of the concession period, $n T_{r} \leq T_{c}$. It means that the two parties make their decisions again at the beginning of the year $\left(n T_{r}+1\right)$ based on the existing

Table 2 - Growth rate for different game results

\begin{tabular}{|c|c|c|c|}
\hline$S$ & $\alpha$ & $\beta$ & $\mu_{i j}$ \\
\hline \hline$\left(S_{G}^{1}, S_{P}^{1}\right)$ & & & $\mu_{11}=b \cdot \frac{w[1+\ln (1+\beta)]}{P(1-\alpha)}$ \\
\hline$\left(S_{G}^{1}, S_{P}^{0}\right)$ & & 0 & $\mu_{10}=b \cdot \frac{w}{P(1-\alpha)}$ \\
\hline$\left(S_{G}^{0}, S_{P}^{1}\right)$ & 0 & & $\mu_{01}=b \cdot \frac{w[1+\ln (1+\beta)]}{P}$ \\
\hline$\left(S_{G}^{0}, S_{P}^{0}\right)$ & 0 & 0 & $\mu_{00}=b \cdot \frac{w}{P}$ \\
\hline
\end{tabular}


performance of the project from year 1 to year $n T_{r}$ and their prediction on its performance in the following years from $n T_{r}+1$ to $T_{c}$.

The value of net social benefit includes RV, residual value when the concession ends, and $B$, the improvement part of level of service enjoyed by the users resulting from investing in the project. The total expected social benefit at the end of the concession period based on the game result $\boldsymbol{S}$ in round $n$ should be represented as follows:

$$
R_{G, n}\left(S_{G}^{i}, S_{P}^{j}\right)=R V_{n}^{i, j}+B_{n}^{i, j}-\theta E, \quad i, j=0,1
$$

$E$ is the total equity investment of this project. The equity share held by the public sector is $\theta E$, and $(1-\theta) E$ for the private sector.

$R V_{n}^{i, j}$ is the expected present value (discounted to year 0 , applicable for all the present value in this paper) of the residual value calculated in round $n$ based on $\left(S_{G}^{i}, S_{P}^{j}\right)$. And it can be broken down as follows:

$$
R V_{n}^{i, j}=r r \cdot\left(I+\sum_{k=n T_{r}+1}^{T_{c}} \frac{M \beta^{2} \gamma_{n}}{(1+d)^{k}}+M_{n}\right), \quad i, j=0,1
$$

where $r r$ is the residual rate and $d$ is the discounted rate. $I$ refers to total investment of the project. The second item in brackets is the expected present value of the total extra maintenance and operation cost the social sector will pay in the following years, regarded as asset appreciation in the future. And $M_{n}$ is the present value of total extra costs that have already been paid in round $n$, regarded as asset appreciation before round $n . M_{n}$ can be obtained by the following recurrence formula:

$$
M_{n+1}=\sum_{k=n T_{r}+1}^{(n+1) T_{r}} \frac{\left.M \beta^{2} \gamma_{n}\right)}{(1+d)^{k}}+M_{n}, \quad M_{0}=0
$$

$\gamma_{n}$ is a binary variable depending on which strategy the private sector chooses in round $n$. If the private sector decides not to make any extra efforts on the project, then $\left(\mathrm{S}_{P}^{0}\right), \gamma_{n}=0$. But if the private sector makes extra efforts on the project, then $\left(\mathrm{S}_{P}^{1}\right), \gamma_{n}=1$.

$B_{n}^{i, j}$ in Equation 4 refers to the expected present value of the increment of the level of service enjoyed by the users at the end of the concession based on $\left(S_{G}^{i}, S_{P}^{j}\right)$ in round $n$.

$$
B_{n}^{i, j}=\sum_{k=n T_{r}+1}^{T_{c}} \frac{w \ln (1+\beta) Q_{i j k} \gamma_{n}}{(1+d)^{k}}+B_{n}, \quad i, j=0,1
$$

The first item of Equation 7 is the expected present value of the total increment of the level of service enjoyed by the users from year $n T_{r}+1$ to $T_{c}$. $B_{n}$ is the present value of the same by round $n$. Similar to $M_{n}, B_{n}$ can also be obtained through a recurrence formula:

$$
\begin{aligned}
& B_{n+1}=\sum_{k=n T_{r+1}}^{(n+1) T_{r}} \frac{w \ln (1+\beta) Q_{i j k} \gamma_{n}}{(1+d)^{k}}+B_{n} \\
& i, j=0,1 \text { and } B_{0}=0
\end{aligned}
$$

As for the private sector, the total expected revenue of the public sector based on $S$ predicted in round $n$ should be represented as follows:

$$
\begin{aligned}
& R_{P, n}\left(S_{G}^{i}, S_{P}^{j}\right)= \\
& =\sum_{k=n T_{r}+1}^{T_{c}} \frac{\left[Q_{i j k} P L-M\left(1+\beta^{2} \gamma_{n}\right)\right]}{(1+d)^{k}}+R_{n}-(1-\theta) E, \\
& i, j=0,1
\end{aligned}
$$

$(1-\theta) E$ is the equity investment of the private sector. The first item of Equation 9 is the present value of the total profit the private sector will get in the following years, and $R_{n}$ represents the part already obtained in round $n$.

$$
\begin{aligned}
& R_{n+1}=\sum_{k=n T_{r}+1}^{(n+1) T_{r}}\left[\frac{\left[Q_{i j k} P L-M\left(1+\beta^{2} \gamma_{n}\right)\right]}{(1+d)^{k}}+R_{n},\right. \\
& i, j=0,1 \text { and } R_{0}=0
\end{aligned}
$$

\section{DECISION MAKING}

After calculating $R_{G, n}\left(S_{G}^{i}, S_{P}^{j}\right)$ and $R_{P, n}\left(S_{G}^{i}, S_{P}^{j}\right)$ in four different conditions indicated in Table 2, the decision making process can be simulated through the static game model shown in Table 3.

Table 3 - The Static Game Model

\begin{tabular}{|c|c|c||}
\hline \hline & $S_{P}^{1}$ & $S_{P}^{0}$ \\
\hline \hline$S_{G}^{1}$ & $R_{G, n}\left(S_{G}^{1}, S_{P}^{1}\right), R_{P, n}\left(S_{G}^{1}, S_{P}^{1}\right)$ & $R_{G, n}\left(S_{G}^{1}, S_{P}^{0}\right), R_{P, n}\left(S_{G}^{1}, S_{P}^{0}\right)$ \\
\hline$S_{G}^{0}$ & $R_{G, n}\left(S_{G}^{0}, S_{P}^{1}\right), R_{P, n}\left(S_{G}^{0}, S_{P}^{1}\right)$ & $R_{G, n}\left(S_{G}^{0}, S_{P}^{0}\right), R_{P, n}\left(S_{G}^{0}, S_{P}^{0}\right)$ \\
\hline
\end{tabular}

For the public sector, if $R_{G, n}\left(S_{G}^{1}, S_{P}^{1}\right)>R_{G, n}\left(S_{G}^{0}, S_{P}^{1}\right)$ and $R_{G, n}\left(S_{G}^{1}, S_{P}^{0}\right)>R_{G, n}\left(S_{G}^{0}, S_{P}^{0}\right)$, which means whichever strategy the private sector chooses, $S_{G}^{1}$ always brings more revenue, the public sector will definitely choose to give subsidy $\left(S_{G}^{1}\right)$. If $R_{G, n}\left(S_{G}^{0}, S_{P}^{1}\right)>$ $R_{G, n}\left(S_{G}^{1} S_{P}^{1}\right)$ and $R_{G, n}\left(S_{G}^{0}, S_{P}^{0}\right)>R_{G, n}\left(S_{G}^{1}, S_{P}^{0}\right)$, the public sector will definitely choose not to give subsidy $\left(S_{G}^{0}\right)$. Otherwise, the public sector should compare $R_{G, n}\left(S_{G}^{1}, S_{P}^{1}\right)+R_{G, n}\left(S_{G}^{1} S_{P}^{0}\right)$ and $R_{G, n}\left(S_{G}^{0}, S_{P}^{1}\right)+$ $R_{G, n}\left(S_{G}^{0}, S_{P}^{0}\right)$ and tend to choose the larger one.

The same logic is applicable to the private sector. If $R_{P, n}\left(S_{G}^{0}, S_{P}^{1}\right)>R_{P, n}\left(S_{G}^{0}, S_{P}^{0}\right)$ and $R_{P, n}\left(S_{G}^{1}, S_{P}^{1}\right)>$ $R_{P, n}\left(S_{G}^{1}, S_{P}^{0}\right)$, the private sector will choose $S_{P}^{1}$. If $R_{P, n}\left(S_{G}^{0}, S_{P}^{0}\right)>R_{P, n}\left(S_{G}^{0}, S_{P}^{1}\right)$ and $R_{P, n}\left(S_{G}^{1}, S_{P}^{0}\right)>R_{P, n}\left(S_{G}^{1}, S_{P}^{1}\right)$, the private sector will choose $S_{P}^{0}$. Otherwise, the 
private sector should compare $R_{P, n}\left(S_{G}^{1}, S_{P}^{1}\right)+R_{P, n}(S$ $\left.{ }_{G}^{0}, S_{P}^{1}\right)$ and $R_{P, n}\left(S_{G}^{1}, S_{P}^{0}\right)+R_{P, n}\left(S_{G}^{0}, S_{P}^{0}\right)$ and tend to choose the larger one.

Consequently, a result of $\left(\gamma_{n}, \pi_{n}\right)$ will be obtained through the above analysis. $\gamma_{n}$ and $\pi_{n}$ are binary variables representing the strategies of the private sector and the public sector, respectively. The meaning of $\gamma_{n}$ has already been introduced above, and $\pi_{n}$ represents whether the public sector will give subsidy in following years. $\pi_{n}=1$ means that the public sector chooses to give subsidy and $\pi_{n}=0$ means no subsidy.

Given the initial data of a project and the value of decision variables: subsidy ratio $\alpha$ and level of efforts $\beta$, the above models can be used to determine the subsidy strategy and the LOE strategy in every round and simulate the performance of the project in the whole operation period.

The simulation process is shown in Figure 2.

Since the optimal value of $\alpha, \beta$, and $T_{r}$ can hardly be obtained via analytic solutions, we set different values for them before the numerical simulation, and choose the best one based on the comparison of different simulation results. In every renegotiation round, the total social benefit $R_{G, n}\left(S_{G}^{i}, S_{P}^{j}\right)$ and total revenue of the private sector $R_{P, n}\left(S_{G}^{i}, S_{P}^{j}\right)$ based on all the strategies in Table 2 should be simulated first. By comparing them as stated above, we can obtain the static game result $\left(\gamma_{n}, \pi_{n}\right)=(i, j)$. Before the next round starts, both sectors will continue to implement the strategies they chose in this round. The process will be finished when the concession period ends. There are four outputs of this model. $\tilde{S}_{G}$ is the present value of the sum of the subsidy the public sector provides for the PPP project in the whole concession.

$\tilde{S}_{G}=\sum_{k=1}^{T_{c}} \frac{\alpha P Q_{i j k} L \pi_{n}}{(1+d)^{k}}$

where $\tilde{R}_{P}$ is the present value of the revenue obtained by the private sector when the concession ends.

$\tilde{R}_{P}=\sum_{k=1}^{T_{c}} \frac{\alpha P Q_{i j k} L-M\left(1+\beta^{2} \gamma_{n}\right)}{(1+d)^{k}}$

The game results in all rounds $\left(\gamma_{n}, \pi_{n}\right)$, $n=1,2, \ldots,\left[\frac{T_{c}}{T_{r}}\right]$ can also be acquired.

In order to determine the decision variables $\alpha$ and $\beta$, a new index, efficiency of fund, is introduced. The efficiency of fund $(S E)$ can be obtained from the following outputs:

$S E=\frac{\tilde{R}_{P}-R_{P}^{0}}{\tilde{S}_{G}}$

where:

$S E$ - efficiency of subsidy use

$R_{P}^{0}$ - revenue of the private sector if the public sector never provides any subsidy

$S E$ - increase in concession revenue caused by a unit of government subsidy. It is a meaningful index, especially when the local government should give support to many projects of public service but with a limited budget. In this situation, a subsidy strategy with the higher value of the $S E$ will be a preferred choice.

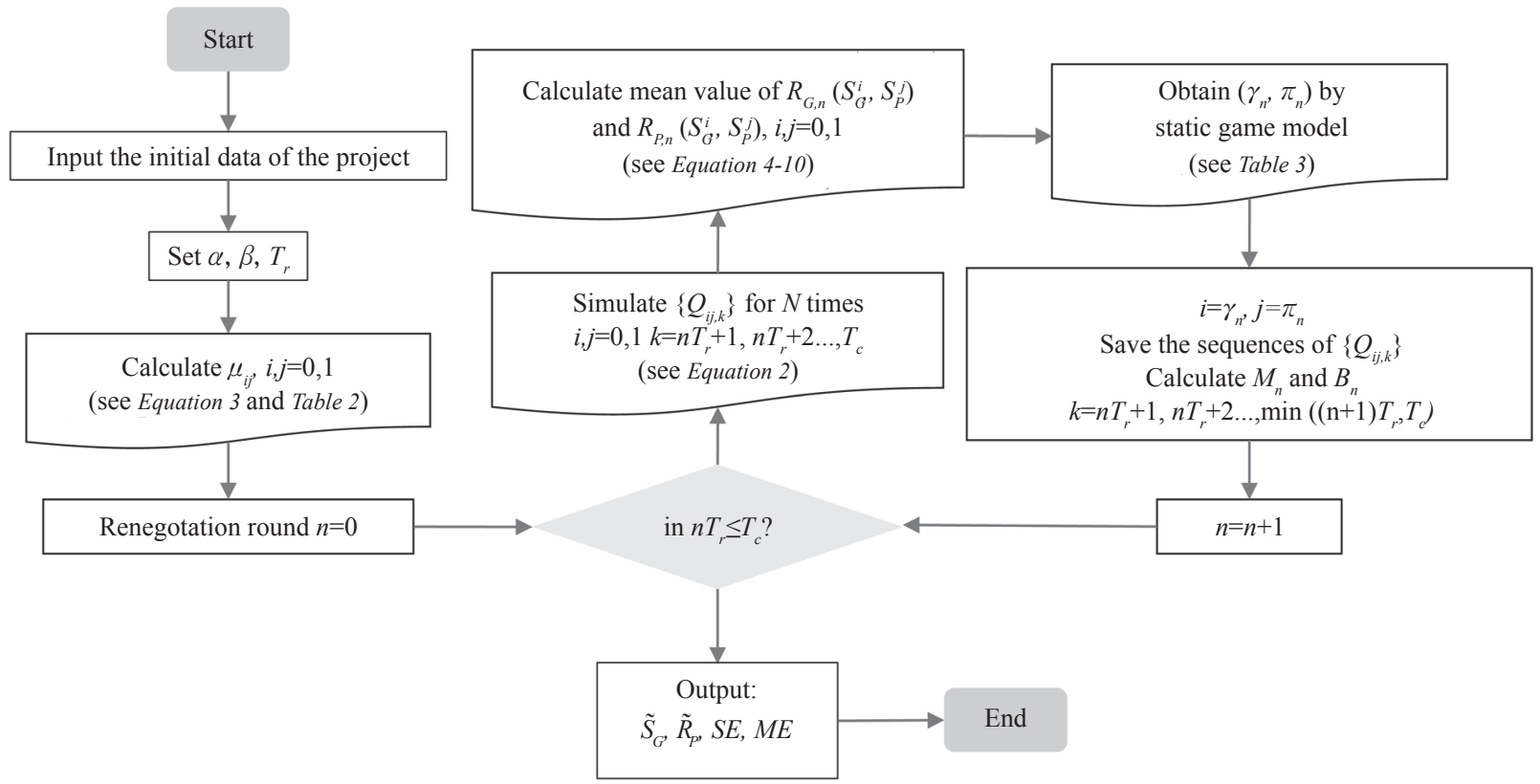

Figure 2-Flow chart of the simulation 
$M E$ - present value of the total extra cost the private sector pays for the project as shown in Equation 14. It indicates a general LOE of the private sector during the whole concession period. A high value of the $M E$ means that the subsidy strategy can effectively arouse the motivation of the private sector to make more efforts.

$$
M E=\sum_{k=1}^{T_{c}} \frac{M \beta^{2} \gamma_{n}}{(1+d)^{k}}
$$

Aiming at a higher $S E$ and $M E$ value, the optimal $\alpha$ and $\beta$ can be obtained. In order to get the optimal value, we set arrays $\alpha=\left[\alpha_{1}, \alpha_{2}, \ldots, \alpha_{l}\right]$ and $\beta=\left[\beta_{1}, \beta_{2}, \ldots, \beta_{m}\right]$ within a proper range, and test the SE and ME values of all combinations to find the optimal solution $\left(\alpha_{o}, \beta_{o}\right)$. In the same manner, the influence of the renegotiation frequency (related to $T_{r}$ ) on $S E$ and $M E$ can also be obtained.

\section{CASE STUDY}

In this section, a numerical simulation of a toll road case is carried out to verify the above model in various conditions. Beijing Xing Yan highway is one of the important rapid channels connecting the city center and the venue of 2019 Expo and 2022 Olympic Winter Games. It is a 4-lane highway with a length of $42 \mathrm{~km}$ and the expected AADT (annual average daily traffic) is about $46,575 \mathrm{pcu}$. The construction started in 2015 and the operation period is from 2019 to 2043. China Railway Construction Corporation (CRCC), a leading construction enterprise in the application of PPPs, has been selected to carry out this project as the private sector. The
BOT (build-operate-transfer) mode is selected in this project, so the project company is responsible for investment, construction, operation, and transference. In order to guarantee the minimal revenue of the private sector and share the revenue risk, the Beijing Municipal Financial Bureau, the financial representative of the public sector, provides the SPV with price subsidy (the gap of contract price and real price for every passenger car unit) in the concession period. A more detailed investment and financing structure of this project is shown in Figure 3.

However, another traffic channel, the Beijing-Zhangjiakou high-speed railway, is also built as part of the transport support for the Winter Olympics. The railway will share part of the traffic volume in this channel, resulting in the Xing Yan highway taking on unexpected revenue risk. Therefore, it is difficult for the public sector to come up with a proper subsidy scheme. Some technical items and input variables of this model are shown in Table 4. There are some values marked with * which cannot be obtained directly from the document but by other means. The reasons for these values are discussed below.

As for the volatility parameter $\sigma$, the standard deviation of the log returns of the regional gross domestic product (GDP) can be a usual proxy [9], because traffic level (i.e., annual traffic volume) is strongly related to the economic growth. GDP series of Beijing from 1999 to 2018 is obtained from the National Bureau of Statistics of China, which indicates a volatility parameter of $3.8 \%$. The annual income is predicted as a linear growth in the feasibility study document [24]. According to the growth

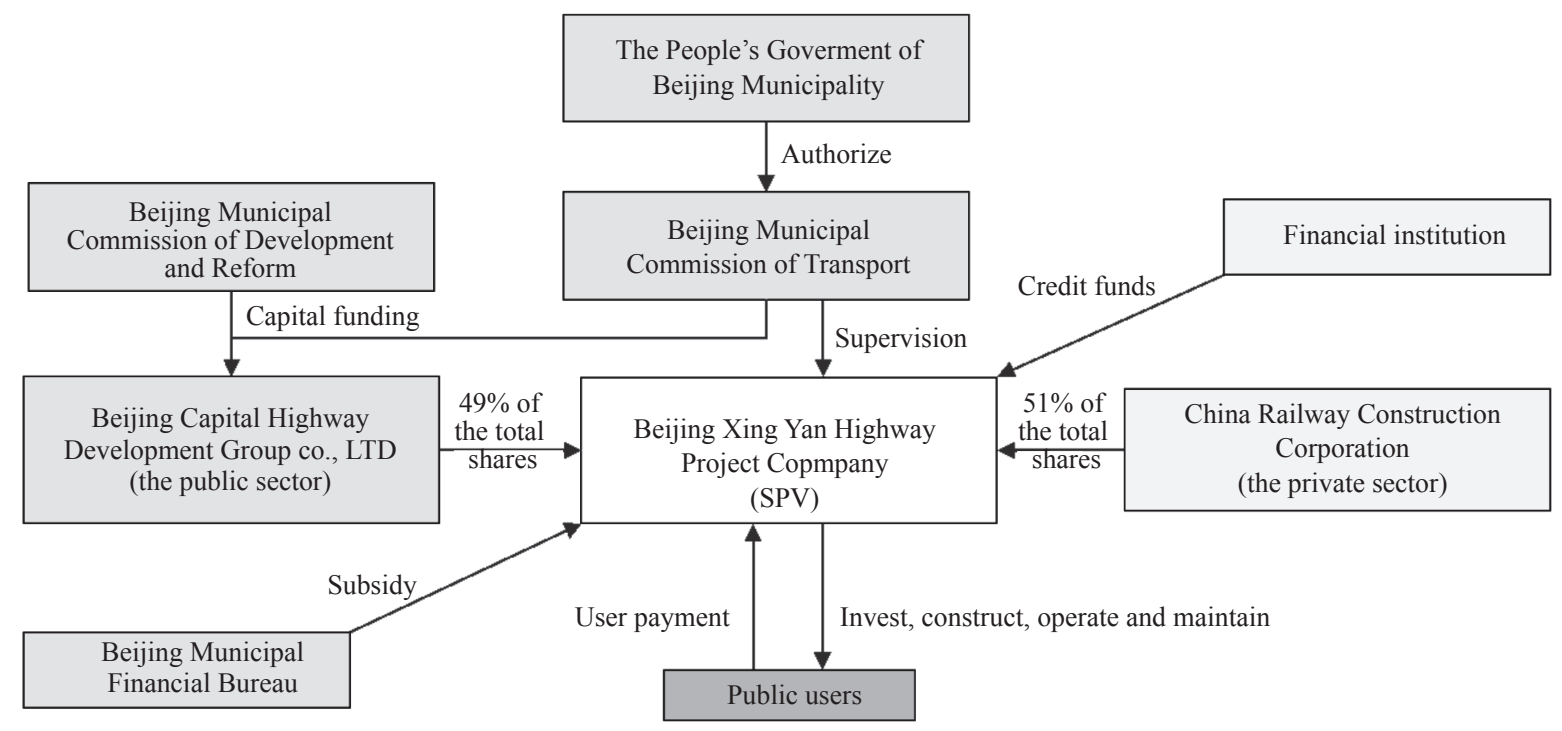

Figure 3 - Investment and Financing Structure of the Beijing Xing Yan Highway PPP Project 
Huang Y, Hu H, Chen J, Dai L. Decision Making on Government Subsidy for Highway Public-Private Partnership Projects...

Table 4 - Values of Input Variables

\begin{tabular}{|c|c|c|c|}
\hline Variables & Definitions & Units & Value \\
\hline$E$ & Equity capital & Million yuan & 6,682 \\
\hline$I$ & Total investment & Million yuan & 13,090 \\
\hline$\theta$ & Equity share of the public sector & $\%$ & 49 \\
\hline$d$ & Discounted rate & $\%$ & 6 \\
\hline$P$ & Toll rate & Yuan/pcu $\cdot \mathrm{km}$ & 0.5 \\
\hline$\sigma^{*}$ & Volatility parameter & $\%$ & 3.8 \\
\hline$b^{*}$ & Growth rate parameter & N/A & 0.02 \\
\hline$M$ & Annual cost & Million yuan & 410 \\
\hline$w^{*}$ & General level of service & Yuan/ pcu $\cdot \mathrm{km}$ & 0.5 \\
\hline$r r$ & Residual rate of the project & $\%$ & 10 \\
\hline
\end{tabular}

Data without * come from the bid document and feasibility report of this project published at: http://www.cpppc.org:8083/ efmisweb/ppp/projectLibrary/getProjInfoNational.do?projId=0ebb60d257c84831b4ce6f1dacd96d64

rate in the document, a growth parameter $b$ of 0.02 is obtained. $w$ can be represented by the average unit price of highway service in the same region, which equals $0.5 \mathrm{CNY} / \mathrm{pcu} \cdot \mathrm{Km}$.

The residual value is assumed to be $10 \%$ of the whole investment.

The demand (annual traffic volume) in the first year is set based on the expected AADT as a random item obeying triangular distribution with lower limit 14 million pcu, upper limit 20 million pcu, and mode 17 million pcu.

Both the subsidy ratio $\alpha$ and the level of efforts $\beta$ are given by an array: $[0.05,0.10, \ldots 0.40]$, with an interval of 0.05 . Besides, the renegotiation cycle $T_{r}$ is given as $[4,5,6]$ (years), which means the two sectors should renegotiate the subsidy approximately every 5 years. The main reason for setting this number is that the term of office of one Chinese local government is 5 years and it is natural that the new government should renegotiate with the private sector on the PPP agreement.

Then, three scenarios will be simulated:

Scenario 1: Both two parties would make decisions in each round based on the methodology proposed in section 3;

Scenario 2: The local government would never provide any subsidy in the concession period but the operator would consider whether it is necessary to make excess efforts as explained in section 3 .

Scenario 3: The local government would always provide subsidy in all the rounds, and the operator would make a choice.
The result of Scenario 2 is a baseline group. $R_{P}^{0}$ equals the total revenue gained by the private sector $\left(\tilde{R}_{P}\right)$ under the circumstance of scenario 2. $\tilde{S}_{G}$ and $\tilde{R}_{P}$ of Scenario 1 and Scenario 3 are used to calculate $S E$ and make comparisons.

Through simulation, the $S E$ and $M E$ values are obtained from all the combinations of $\alpha, \beta$, and $T_{r}$ in the above range. In order to present the distribution of the $S E$ and $M E$, all the points $(\alpha, \beta, S E)$ and $(\alpha, \beta, M E)$ are plotted in a 3D mesh scatter form. Figure 4 and Figure 5 show the 3D mesh scatter plots of the $S E$ and $M E$ given various $\alpha$ and $\beta$ when the renegotiation cycle length $T_{r}=4,5$, and 6 in Scenario 1 and Scenario 3 (in Scenario 2, the public sector does not provide any subsidy, so we cannot calculate the $S E$ for Scenario 2).

The optimal point is defined as the combination of the government subsidy ratio and the private sector's level of effort with the maximum $S E$ (the optimal efficiency of fund use) or the maximum $M E$ (when the private sector spontaneously pays a maximum extra cost for operation and maintenance). Table 5 shows the value of the optimal SE, ME (maximal point) and the corresponding $\left(\alpha_{o}, \beta_{o}\right)$ for Scenario 1 and Scenario 3.

According to the numerical simulation results in Figures 4 and 5, the subsidy efficiency (SE) can analogously be regarded as a decreasing function about $\alpha$, and an increasing function about $\beta$. And when $\beta$ is very high, $S E$ grows rapidly given a decrease in $\alpha$. It means that in order to get a higher efficiency on the government fund, the local government is supposed to decrease the subsidy ratio and make more 

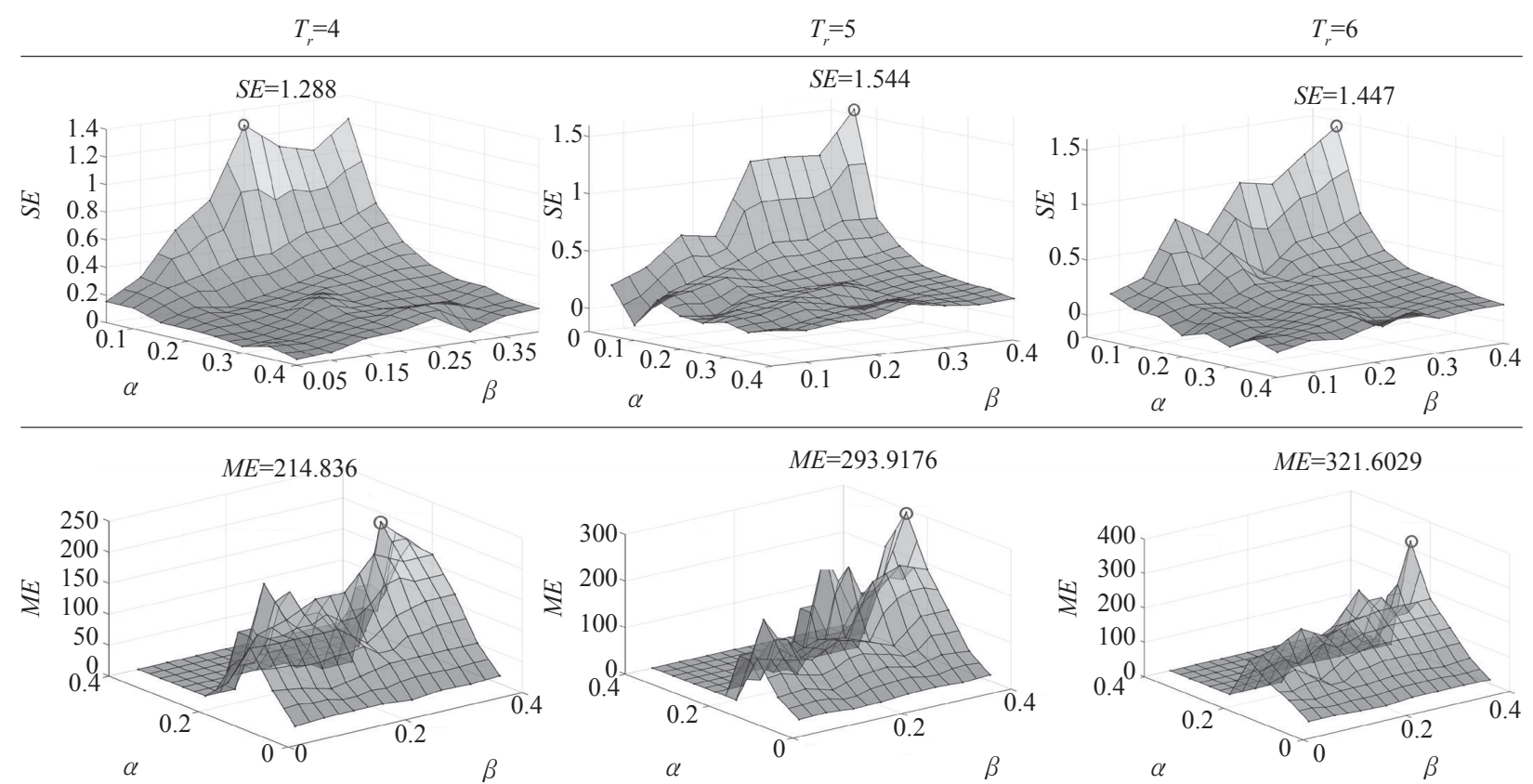

The Optimal Point

Figure 4-3D mesh scatter plots of SE and ME in Scenario 1
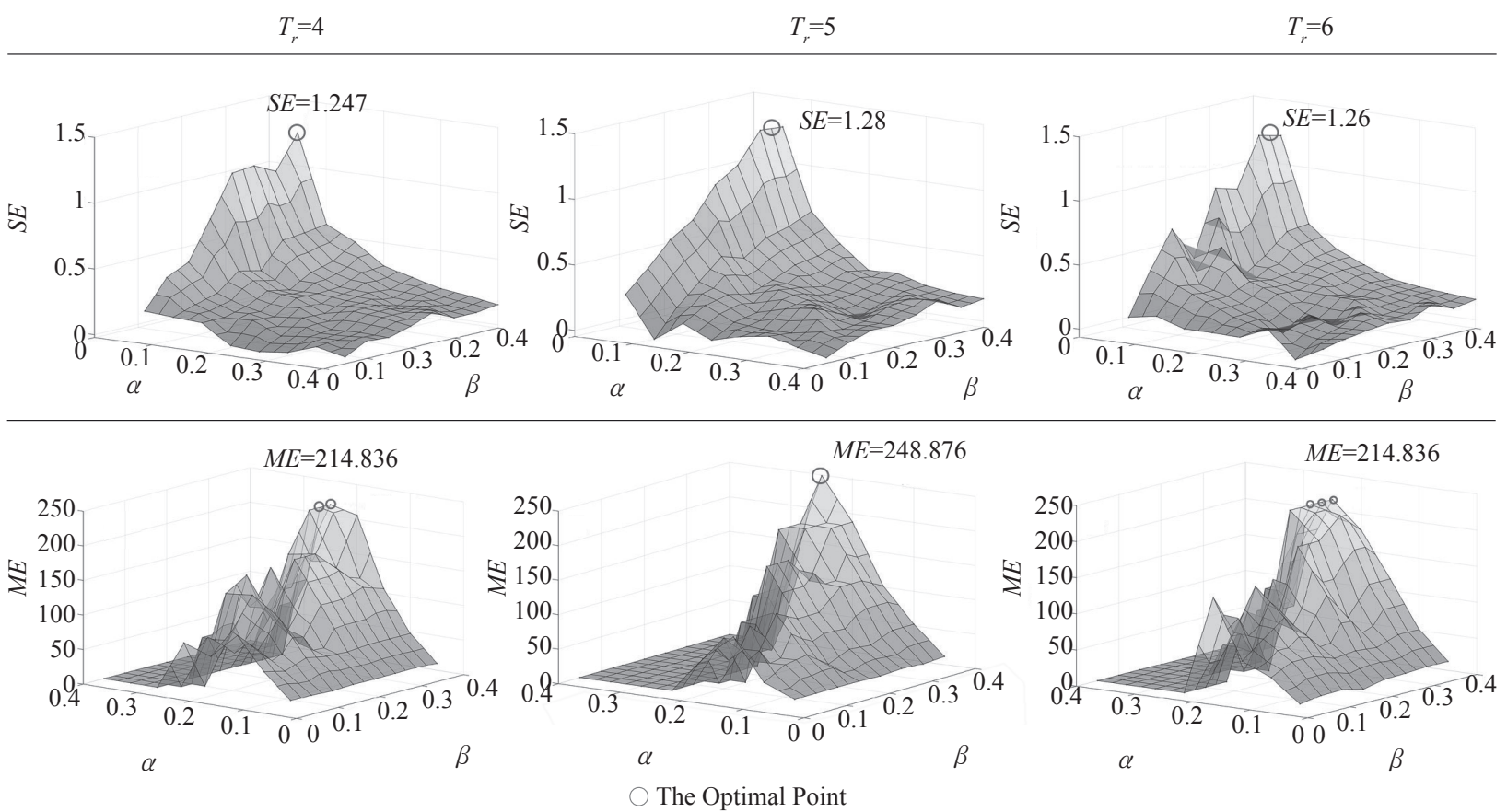

Figure 5-3D mesh scatter plots of SE and ME in Scenario 3

efforts on the incentive policies. The results stress the importance of improving the motivation of private sectors on doing the best on the project rather than merely granting them subsidy.

As for $M E$, given the LOE, the relationship between $\alpha$ and the total excess efforts of the private sector cannot be simplified as a linear function, but a high subsidy ratio is more likely to increase the motivation of the private sector to be devoted.
Moreover, Table 5 shows that the optimal points of $S E$ and $M E$ are mainly located in different areas in the coordinate. It means that there is a trade-off between the high level of $S E$ and $M E$. If the government should subsidize many projects with a limited budget, it is supposed to carry out the strategy with the maximum $S E$. And if the government is not confronted with any fiscal stress, it can choose the strategy with the maximum $M E$. 
Huang Y, Hu H, Chen J, Dai L. Decision Making on Government Subsidy for Highway Public-Private Partnership Projects...

Table 5 - Optimal combinations of the case project

\begin{tabular}{||c|c|c|c|c||}
\hline \multicolumn{2}{||c|}{} & 4 & 5 & 6 \\
\hline \multirow{3}{*}{ Scenario 1 } & Optimal SE $/\left(\alpha_{o}, \beta_{o}\right)$ & $1.288 /(0.05,0.25)$ & $1.544 /(0.05,0.4)$ & $1.448 /(0.05,0.4)$ \\
\cline { 2 - 5 } & Optimal ME $/\left(\alpha_{o}, \beta_{o}\right)$ & $214.836 /(0.35,0.25)$ & $293.9167 /(0.40,0.25)$ & $321.6029 /(0.40,0.25)$ \\
\hline \multirow{3}{*}{ Scenario 3 } & Optimal SE / $\left(\alpha_{o}, \beta_{o}\right)$ & $1.247 /(0.05,0.40)$ & $1.28 /(0.05,0.35)$ & $1.26 /(0.05,0.35)$ \\
\cline { 2 - 5 } & Optimal ME / $\left(\alpha_{o}, \beta_{o}\right)$ & $\begin{array}{c}214.836 /(0.35,0.25), \\
(0.40,0.25)\end{array}$ & $248.876 /(0.40,0.25)$ & $\begin{array}{c}214.836 /(0.30,0.25), \\
(0.35,0.25),(0.4,0.25)\end{array}$ \\
\hline
\end{tabular}

The above discussion is about how the subsidy ratio and level of efforts will influence $S E$ and $M E$. Next, a comparison of the $S E$ and $M E$ between Scenario 1 and Scenario 3 is carried out to verify whether an optional and mutable subsidy scheme can both effectively trigger the motivation of the private sector and the efficiency of the fund use of the government. Table 6 shows the $\max \triangle S E$, average $\triangle S E$, $\max \triangle M E$, and average $\triangle M E$ where $\Delta=$ Scenario 1 - Scenario 3.

A positive mean value of $\triangle S E$ in all $T_{r}$ verifies that an optional and mutable subsidy scheme can improve the efficiency in the government fund using. However, not all the average $\triangle M E$ are positive, which means the public sector's strategy of not providing subsidy may not trigger the private sector to pay the extra cost.

Finally, we come up with two subsidy schemes and their corresponding game outcome for this PPP case as shown in Table 7. In Scheme 1, given a renegotiation cycle of 5 years, the public sector provides $5 \%$ of the contract price for 20 years, and the private sector will not make any extra efforts in the operation period. In this situation, the local government could realize a maximum efficiency of fund using and at the same time the private sector could gain a net revenue of 689 million CNY. This subsidy scheme is suitable for the local government

Table 6 - Comparison of SE between Scenario 1 and 3

\begin{tabular}{||c|c|c|c||}
\hline & 4 & 5 & 6 \\
\hline \hline $\max \Delta S E$ & 0.2278 & 0.2454 & 0.2189 \\
\hline average $\Delta S E$ & 0.0096 & 0.0146 & 0.0180 \\
\hline $\max \Delta M E$ & 52.4257 & 248.8764 & 126.0064 \\
\hline average $\Delta M E$ & -5.1181 & 6.0962 & 0.5514 \\
\hline
\end{tabular}

Table 7 - Subsidy scheme for the Xing Yan Highway PPP project based on the iteration game model simulatio

\begin{tabular}{|c|c|c|c|c|c|c|}
\hline \multicolumn{7}{|c|}{ Subsidy scheme 1: applicable for public sector with limited fiscal budget } \\
\hline \multirow{3}{*}{ Game results } & $\begin{array}{c}\text { Concession } \\
\text { year }\end{array}$ & $1-5$ & $6-10$ & $11-15$ & $16-20$ & $21-25$ \\
\hline & $\begin{array}{c}\text { The public } \\
\text { sector } \\
\alpha=0.05\end{array}$ & Give subsidy & Give subsidy & Give subsidy & Give subsidy & No subsidy \\
\hline & $\begin{array}{c}\text { The private } \\
\text { sector } \\
\beta=0.05\end{array}$ & $\begin{array}{l}\text { No extra } \\
\text { efforts }\end{array}$ & No extra efforts & No extra efforts & No extra efforts & No extra efforts \\
\hline \multicolumn{7}{|c|}{ Subsidy scheme 2: applicable for public sector with enough funding } \\
\hline \multirow{3}{*}{ Game results } & \multicolumn{2}{|c|}{ Concession year } & $1-6$ & $7-12$ & $13-18$ & $19-25$ \\
\hline & \multicolumn{2}{|c|}{ The public sector $\alpha=0.40$} & Give subsidy & Give subsidy & Give subsidy & Give subsidy \\
\hline & \multicolumn{2}{|c|}{ The private sector $\beta=0.25$} & $\begin{array}{l}\text { Make extra } \\
\text { efforts }\end{array}$ & $\begin{array}{l}\text { Make extra } \\
\text { efforts }\end{array}$ & $\begin{array}{l}\text { Make extra } \\
\text { efforts }\end{array}$ & No extra efforts \\
\hline
\end{tabular}


that suffers from a fiscal stress. In another subsidy scheme, given a renegotiation cycle of 6 years, the public sector provides $40 \%$ of the contract price in all the rounds, and the private sector makes $25 \%$ extra efforts to get more revenue from the concession year 1 to 18 gaining a net revenue of 1212 million CNY. This scheme is suitable for the local government with enough fiscal funding.

To sum up, the following conclusions could be drawn based on the above discussion on the numerical simulation:

- To improve efficiency of fund using $(S E)$ : a subsidy scheme that is flexible and mutable instead of set in stone improves $S E$; also, increasing the subsidy ratio $(\alpha)$ results in decreasing $S E$ while the private sector's high level of efforts $(\beta)$ leads to an increase in $S E$.

- To improve the private sector's willingness to make extra efforts $(M E)$ : the absence of government subsidy may not increase the motivation of the private sector, and conversely, the government's fiscal support (higher $\alpha$ ) is the only factor that can induce the private sector to make more efforts.

- A trade-off between the subsidy scheme with optimal $S E$ and that with optimal $M E$ : it depends on the budget of the local government; for the public sector with limited budget, $S E$ should be improved in decision making on the subsidy, and for the public sector with enough funding, improving $M E$ should be their primary consideration.

\section{DISCUSSION}

Numerous existing studies have focused on the decision making regarding the government subsidy in toll road PPP projects, and most of these decision-making processes are completely based on the revenue prediction for the private sector, aiming to guarantee the profitability of the project. However, the incentive effect of the subsidy on the private sector is scarcely addressed within the existing models. In order to find out how the interactions between the stakeholders' decision-making behaviors will influence the PPP project and the subsidy scheme, this paper proposes an iteration game model to simulate the behaviors of stakeholders throughout the concession period and help the public sector make decisions on the subsidy scheme. The main contributions this paper has made to the body of knowledge can be summarized as follows:
- Creating new indicators: $S E$ and $M E$ for subsidy decision making. Existing studies usually choose NPV as the evaluation indicator of the subsidy scheme, for they focus on the improvement of financial feasibility and the reduction in investment risk caused by the subsidy. In this paper, a good subsidy scheme is defined as one that can increase the motivation of the private sector to make more efforts on improving the level of service. $S E$ evaluates the incentive effect of every unit subsidy, while $M E$ indicates the total extra efforts the private sector makes in the operation period. A subsidy scheme with the maximum $S E$ can provide the local government with the most economical alternative especially when it suffers from fiscal stress. And a scheme with the maximum $M E$ is the one that can trigger the most extra investment from the private sector and generates the most social benefit. This paper expands the criteria of determining the government subsidy scheme from a finance-oriented perspective to an efficiency-oriented one.

- Developing an iteration game model framework for subsidy decision making. As stated in the introduction section, there are typically two steps to determine the subsidy scheme - revenue prediction and decision making. The previous logic is that the financial performance of the project determines the subsidy scheme. However, the iteration game model framework considers the feedback loop: the game results of the two sectors will influence the financial performance of the project, and with the project's financial performance changed, the stakeholders will adjust their strategies in order to generate more revenue or more social benefit. In this way, the model can analyze the relationship between the stakeholders' behaviors and the performance of the project in a dynamic perspective.

This paper proposes the iteration game model to help the local government create a better subsidy scheme, and applies this model in a case study based on the Beijing Xing Yan highway PPP project. Based on the numerical simulation results, some suggestions and remarks are also summarized as follows:

- The local government is suggested to create a more flexible subsidy scheme. In the above case study, we compared the $S E$ of different scenarios and verified that an optional and mutable subsidy scheme, in which the government can weigh the 
pros and cons and can change its strategy, will improve the efficiency of fund using. Therefore, the local government is suggested to be allowed to adjust its subsidy expenditure according to the real revenue of the project during the concession period. The significance of such a scheme lies in sparing fiscal fund for the local government with limited budget, and also promoting the adaptive and agile management of highway PPP projects.

- Providing the private sector with incentive and reward policy instead of merely cash support. The simulation results show that higher subsidy ratio $(\alpha)$ can stimulate the private sector to make more extra efforts $(M E)$, but can also have a negative effect on $S E$, which seems to be a paradox. To solve this problem, the local government is suggested to replace the subsidy with other compensation methods. The application of the PPP project + resource compensation bundling mode should be encouraged. For instance, the MTR (public transport network serving Hong Kong) is a very successful PPP project with "rail + property" mode. The public sector provides land development rights, which increases total revenue and improves investment return. Thus, the railway operator is encouraged to carefully protect the surrounding land and environment. Similarly, for a highway, the public sector can provide commercial development rights of the logistics parks near the highway or in the rest area.

\section{CONCLUSION}

This paper proposes an iteration game model combing game theory and real option theory to determine the subsidy item in highway PPP projects in the concession period. Different from the traditional method, this research regards the decision making of the public and the private sectors as a recurrent action based on the present situation of the project. It considers that every decision the stakeholders make will have an influence on the performance of the project and predicts project performance iteratively by applying the real option theory. Besides, it takes into account the interactions of the decision-making behaviors of the two sectors in every negotiation and describes it through a strategy game model. Last but not least, this paper defines the indicators $S E$ and $M E$ to evaluate the efficiency of government fund using and the incentive effect of the subsidy, which used to be ignored.
However, it should be noted that this study simplifies the behaviors of the two sectors to be binary variables. It would be more convincing if the subsidy ratio and the level of efforts were given as a distribution. In addition, the model is based on a much idealized assumption of no renegotiation cost, and it would be more useful in practice if a more efficient and low-cost renegotiation mechanism was proposed. These more complicated situations can be explored in further studies.

黄显傑, 胡昊, 陈晋进, 戴否

\section{应用一种迭代博恋模型为中国高速公路PPP项 目进行政府补贴决策}

\section{摘要}

政府补贴是政府与社会资本合作 $(P P P)$ 项目中 一项重要的政府支出责任。然而, 不合理的政府补 贴策略会引起补助不足或过度补贴的问题。相比传 统模式下在项目初始阶段就制定一个不变的政府补 贴策略, 于项目特许经营期内进行周期性的、迭代 的补贴策略再谈判可能会使政府补贴更加符合项目 实际的运营情况。本文结合博弯论与实物期权理论 建立了一种迭代博峦模型, 用以描述这种周期性的 决策过程。其中的策略博竕模型用来刻画利益相关 者各自决策行为的互相影响, 而实物期权理论是用 来预测在他们决策结果下的项目未来收益。此外, 本文还构建了两个新的指标：资金效率 $(S E)$ 和社会 资本总额外投入 $(M E)$, 分别用来评估每一单位补 贴引起的项目额外收益, 和补贴的总激励作用。基 于中国北京兴延高速 $P P P$ 项目案例, 将该迭代博弯 模型应用于案例数值分析当中。结果显示, 相比仅 仅给予资金上的支持，地方政府更应该采取激励性 措施，鼓励社会资本为项目投入更多。后续研究将 在本文所提出的模型基础上, 细化利益相关者更复 杂的决策行为。

\section{关键词}

政府与社会资本合作模式; 政府补

贴; 博亦论; 实物期权;

决策; 高速公路案例分析

\section{REFERENCES}

[1] China PPP Center. National PPP Information Platform Project Management Library 2019. Available from: http://www.cpppc.org/zh/pppjb/8718.jhtml [Accessed 15th Nov. 2020].

[2] Qingxue L, Hao H. How to Identify Spurious Transportation Public-Private Partnership Projects. 2018 IEEE Technology and Engineering Management Conference (TEMSCON). IEEE; 2018. p. 1-6. DOI: 10.1109/TEMSCON.2018.8488438

[3] Lara Galera A, Sanchez Solino A, Guirao Abad B. Sharing Risks in Toll Motorway Concessions: Subsidies as 
Real Options on Traffic Volume. Journal of Infrastructure Systems. 2018;24(4).

[4] Shen LY, Li H, Li QM. Alternative concession model for build operate transfer contract projects. Journal of Construction Engineering and Management. 2002;128(4): 326-30.

[5] Ye SD, Tiong RLK. NPV-at-risk method in infrastructure project investment evaluation. Journal of Construction Engineering and Management. 2000;126(3): 227-33.

[6] Shen LY, Wu YZ. Risk concession model for build/operate/transfer contract projects. Journal of Construction Engineering and Management. 2005;131(2): 211-20.

[7] Brandao LET, Saraiva E. The option value of government guarantees in infrastructure projects. Construction Management and Economics. 2008;26(11): 1171-80.

[8] Kim B, Lim H, Kim H, Hong T. Determining the Value of Governmental Subsidies for the Installation of Clean Energy Systems Using Real Options. Journal of Construction Engineering and Management. 2012;138(3): 422-30.

[9] Brandao LE, Bastian-Pinto C, Gomes LL, Labes M. Government Supports in Public-Private Partnership Contracts: Metro Line 4 of the Sao Paulo Subway System. Journal of Infrastructure Systems. 2012;18(3): 218-25.

[10] Song J, Song D, Zhang D. Modeling the Concession Period and Subsidy for BOT Waste-to-Energy Incineration Projects. Journal of Construction Engineering and Management. 2015;141(10): 04015033.

[11] Wang J, Wang Q, Feng J. Study on the Decision Making of Concession Period for PPP Highway Based on Subsidies of Government. International Conference on Construction and Real Estate Management (ICCREM 2017), 10-12 Nov. 2017, Guangzhou, China. 2017. p. 337-45.

[12] $\mathrm{Hu} \mathrm{H}, \mathrm{Zhu}$ Y. Social Welfare-Based Concession Model for Build/Operate/Transfer Contracts. Journal of Construction Engineering and Management. 2015;141(1).

[13] Feng K, Wang S, Li N, Wu C, Xiong W. Balancing public and private interests through optimization of concession agreement design for user-pay PPP projects. Journal of Civil Engineering and Management. 2018;24(2): 116-29.

[14] Shen LY, Bao HJ, Wu YZ, Lu WS. Using bargain- ing-game theory for negotiating concession period for BOT-type contract. Journal of Construction Engineering and Management. 2007;133(5): 385-92.

[15] Sharafi A, Taleizadeh AA, Amalnicka MS. Fair Allocation in Financial Disputes Between Public-Private Partnership Stakeholders Using Game Theory. Service Science. 2018;10(1): 1-11.

[16] Feng K, Wang S, Wu C, Xia G, Hu W. Optimization of Concession Period for Public Private Partnership Toll Roads. Inzinerine Ekonomika-Engineering Economics. 2019;30(1): 24-31.

[17] Mahani I, Tamin RZ, Pribadi KS, Wibowo A. Evaluation of Implementation Viability Gap Funding (VGF) Policy on Toll Road Investment in Indonesia. In: Saloma, Borgan WR, Buntoro F, Victor, editors. $3^{\text {rd }}$ International Conference on Construction and Building Engineering. AIP Conference Proceedings. 2017;1903(1).

[18] Skietrys E, Raipa A, Bartkus EV. Dimensions of the efficiency of public-private partnership. Engineering Economics. 2008;58(3): 45-50.

[19] Carmichael J. The Effects of Mission-Oriented Public R \& D Spending on Private Industry. The Journal of Finance. 1981;36(3): 617-27.

[20] Guellec D, Van Pottelsberghe De La Potterie B. The impact of public R\&D expenditure on business R\&D. Economics of Innovation and New Technology. 2003;12(3): $225-43$.

[21] Liu H, Xiao M-F, Tang Q-Q. Incentive and Crowding-out Effects of R\&D Subsidy on Companies' R\&D Expenditures_-Empirical Analysis Based on the Data of Chinese Listed Companies. Economic Management Journal. 2012;4.

[22] $\mathrm{Hu}$ J, Zhou M. The Impact of Government Subsidies on Corporate R\&D: An Overview. DEStech Transactions on Economics, Business and Management. 2019(ssemr).

[23] Dixit AK, Dixit RK, Pindyck RS. Investment under uncertainty. Princeton University Press; 1994.

[24] China PPP Center. Feasibility Study Report of Xing Yan Highway Project, 2014. Available from: https://www. cpppc.org:8082/inforpublic/homepage.html\#/projectDetail/0ebb60d257c84831b4ce6f1dacd96d64 [Accessed 15th Nov. 2020]. 